\title{
MIGRACIÓN Y ACTIVISMO LITERARIO: LA INTERVENCIÓN SOCIAL Y POÉTICA DE WASHINGTON CUCURTO EN LA ARGENTINA ACTUAL ${ }^{1}$
}

\section{Ben BOLLIG}

\author{
St Catherine's College, University of Oxford
}

凤 $\begin{aligned} & \text { umerosas reseñas sobre la obra de Washington Cucurto, seudónimo de } \\ & \text { Norberto Santiago } \operatorname{Vega}^{2} \text { (Quilmes, Provincia de Buenos Aires, 1973), se } \\ & \text { centran en el exceso y la vulgaridad presentes en su prosa y su poesía. Los }\end{aligned}$ críticos se dividen en dos grupos: los que ven este exceso y vulgaridad como algo positivo y los que opinan lo contrario ${ }^{3}$. Beatriz Sarlo, en un estudio muy citado, publicado por primera vez en Punto de vista, demuestra su preferencia por esta última postura:

Le interesa la vulgaridad de lo que puede ser dicho, con las palabras de la música más popular [...]. A diferencia de Arlt, [...] la literatura de Cucurto se ubica a gusto en ese mundo.

Por supuesto, hay tedio en la repetición, pero como las palabras que se repiten son tan extrañas a la literatura, nadie lo señala porque la sorpresa del exotismo social se combina con el peligro de incorrección ideológica que amenaza a quienes lean «mal» las voces de Cucurto. (Sarlo, 2006: 479)

\footnotetext{
${ }^{1}$ Una versión anterior de este texto fue leída en la reunión que la American Comparative Literature Association celebró en abril de 2010 en Nueva Orleans bajo el rótulo "Creoles, Diasporas, Cosmopolitanisms". Conste mi agradecimiento por el apoyo financiero de la Universidad de Leeds para la realización del viaje. La versión actual fue leída en la Universidad de Santiago de Compostela en noviembre de 2010. Agradezco al Profesor Arturo Casas su amable invitación, y al público de alumnos y profesores de la universidad la generosidad de sus intervenciones durante la conferencia. Una versión del estudio se publicó en inglés en mi libro Modern Argentine Poetry. Displacement, Exile, Migration (Cardiff, University of Wales Press, 2011). Le agradezco a Laura Cantora su ayuda con la traducción de este texto.

${ }^{2}$ Hablaré de Washington Cucurto cuando a éste se le reconoce como el autor de las obras citadas. Utilizo el nombre de Santiago Vega al hablar de eventos y detalles de la vida real y la carrera profesional del autor.

${ }^{3}$ Cucurto incluyó una selección de los comentarios más negativos, y en ocasiones insultantes, en la cubierta interior de El curandero de amor (2006).
} 
Sarlo no muestra temor ante la posibilidad de ser tachada de políticamente incorrecta o acusada de interpretar la obra de Cucurto de forma errónea. Argumenta que Cucurto escribe como alguien que no sabe escribir, que escribe para «los lectores educados» que buscan fantasía y vitalidad exótica. De este modo, Cucurto se encuentra en medio de una paradoja: a pesar de sus intentos por rechazar el realismo, su obra se ve inmersa en esta tradición de pequeña burguesía bien-pensante, una tradición que después de la influyente obra de Osvaldo Lamborghini, deja de constituirse como algo con propósito difamatorio para convertirse en una «sana diversión» (478).

Dos aspectos de la reseña de Sarlo son comunes entre las críticas desfavorables a la obra de Cucurto: la comparación con otros escritores de clase trabajadora (Roberto Arlt, en este caso) y sus vínculos o dependencias con la cumbia, en especial con la variedad de su Argentina natal, la cumbia villera. Sin embargo, yo argumentaría que Sarlo se equivoca al simplificar las complejidades del estilo de Cucurto, tendencia por otra parte común en los muchos ensayos, reseñas y artículos periodísticos sobre Cucurto que se localizan en publicaciones argentinas e internacionales. Me gustaría sugerir que esta simplificación se vincula con tres tendencias de la crítica. En primer lugar, un interés excesivo por la prosa de Cucurto, en particular por su novelas Cosa de negros (2003) y Las aventuras del Sr. Maíz (2005), en detrimento de su obra en verso, lo cual, como consecuencia, genera una tendencia a tratar sus poemas como prosa, centrándose en personajes y argumento, y dejando de lado aspectos rítmicos y en general formales. En segundo lugar, una infravaloración del esfuerzo literario que hay detrás de su obra, tanto en la forma como en términos de referencias intertextuales. Por último, la excesiva importancia otorgada al contexto en el que se enmarca la obra, tanto por atención a la personalidad del autor como por las condiciones del proyecto editorial Eloísa Cartonera.

Nos encontramos pues ante una paradoja, ya que, si nos centramos en el contenido cultural (sobre qué hablan las historias y los poemas de Cucurto), adoptaremos un punto de vista formalista a través del cual se incide en la función social de los textos a través del contraste y del contexto, en lugar de analizar el objeto cultural en sí. Aplicando esa perspectiva, como señala George Yúdice (2003: 23), nos arriesgamos a convertir la cultura en simple recurso político. En términos kantianos, nos concentraríamos en «la forma del pensamiento en general, sin considerar los objetos» (Kant, 1790: 7). De este modo, en efecto, la poesía de Cucurto se valora por las circunstancias y el contexto en el que emerge, así como por la forma en la que se publica y se da a conocer, sin prestar suficiente atención a lo realmente escrito. Esta tendencia se puede apreciar incluso en los análisis más sofisticados y documentados sobre Cucurto y sobre el proyecto Eloísa Cartonera. 
Epplin (2007: 394-396), por ejemplo, sitúa el trabajo de la editorial cartonera en un contexto de comercialización del saber y, apoyándose en los análisis de David Harvey, en un marco general consistente en la financiarización de todo. Traza de este modo paralelos sorprendentes entre los fabricantes artesanales de libros y los últimos progresos de la era digital. Eloísa sería, según Epplin, un proyecto abiertamente comunitario, pero aun así buscaría además ese tipo de existencia fugaz que caracteriza la actividad en línea, por lo que estaría incorporando elementos consustanciales al fordismo y a la vez a lo efímero, condición central de la joven era de internet. Por otra parte, Epplin valora de forma positiva el potencial de Eloísa Cartonera para convocar una economía de solidaridad a través de sus formas de producción. No disputaré la evaluación de Epplin, aunque me parece que en su análisis falta una mención explícita al contenido de los libros. Se trata quizás de un desafortunado efecto secundario del interés de Epplin por el libro como artefacto, que no deja suficiente espacio para una atención pareja sobre lo que en términos literarios ocurre en sus páginas. En particular, Epplin no menciona el papel central de Cucurto como activista cultural dentro del colectivo, tampoco su referencialidad como escritor publicado por el colectivo. En otro orden de cosas, se echa en falta una mención sobre la relación existente entre Eloísa y la reciente y más innovadora literatura argentina, vehículada tanto a través de la publicación de jóvenes poetas como mediante el premio de novela corta promovido.

Si uno de los recordatorios más evidentes del colapso económico y político argentino de 2001 fue la emergencia de los cartoneros, o recicladores no oficiales, visibles incluso por los barrios más afluentes de Buenos Aires, no resulta sorprendente que los efectos culturales de la crisis encontraran una notable repercusión poética en la obra de un escritor fuertemente ligado al cartonerismo ${ }^{4}$. Santiago Vega comenzó a publicar poemas en la década de 1990, bajo el tutelaje de los editores de la importante revista poética 18 Whiskies (importante pese a su breve trayectoria). Entre ellos, Fabián Casas y Juan Desiderio. Fue además, junto al influyente poeta Daniel Durand y algunos otros, miembro de la editorial independiente Ediciones DelDiego, importante centro para jóvenes poetas emergentes que fracasó al estallar la crisis económica de 2001.

Con la devaluación del peso, el precio del cartón reciclado subió de forma desorbitada, convirtiendo la recolección clandestina de cartón en un negocio lucrativo. Junto con otros escritores y diseñadores, Vega encontró la forma de combinar el cartonerismo con la literatura, pagando a los cartoneros tres veces el precio de mercado por los cartones y empleando a jóvenes colectores para el diseño, producción y distribución de unos ejemplares únicos, hechos a mano. Vega comenzó entonces a

\footnotetext{
${ }^{4}$ Sobre el arte en Argentina durante la década de 2000, y en particular sobre la emergencia de nuevas prácticas y grupos como consecuencia o respuesta a la crisis, véase Giunta (2009).
} 
utilizar el seudónimo Washington Cucurto en entrevistas y también en los textos de su autoría. El nombre elegido para la iniciativa fue el de Eloísa Cartonera. Poco a poco fue sumando trabajos de artistas inéditos y otros de escritores reconocidos, entre los cuales acabarían contándose los de Ricardo Piglia, César Aira o el propio Cucurto. La cubierta de cada libro es de cartón, pintada a mano; las páginas interiores son todas ellas fotocopias. Se trata de un formato que se adapta bien a la poesía y a las historias cortas, o incluso a las novelas, tres de las modalidades principales en la obra de Cucurto hasta la fecha. Los libros se venden con éxito en las librerías, dentro y fuera de Buenos Aires, y la editorial localizó su sede en el distrito de Almagro, para posteriormente pasar al barrio de La Boca.

En su reciente obra El tractor, Cucurto describe el proyecto como sigue:

¡Cómo les explico, señores lo que es una cartonería en Buenos Aires!
No hay palabras para semejante despropósito de amor. [...]
Pero es difícil explicarles con lujo de detalles qué es una cartonería.
Nadie lo sabe, ni siquiera nosotros (Cucurto, 2009b: 15).

El proyecto editorial cartonero es ahora una realidad en muchas ciudades de América Latina. Se pueden encontrar iniciativas similares en Brasil, Chile, Paraguay, Perú y México, con algunos cartoneros/as que llegaron incluso a alcanzar cierta fama (Friera, 2007). Como prueba de la resonancia internacional que estas iniciativas están obteniendo, cabe destacar la conferencia sobre las ediciones cartoneras que tuvo lugar en la Universidad de Wisconsin-Madison en octubre de 2009. Todos estos detalles resultan sin duda pertinentes, pero mi argumento es que centrarse en el aspecto sociológico de la obra de Cucurto oscurece un tanto la relevancia de su escritura.

El seudónimo escogido por Washington Cucurto posee un aire literario contemporáneo. Recuérdese que Washington Noriega es un personaje de las novelas de Juan José Saer: en su novela La pesquisa (1994) una parte del argumento hace referencia a las obras que este escritor ficticio deja incompletas a su muerte, situación quizás inspirada por la peripecia de un amigo de Saer, el poeta Juan L. Ortiz. El nombre Washington Cucurto, por otra parte, es típicamente caribeño, con resonancias del sueño norteamericano de democracia y libertad, pero es asimismo una broma relativa al tartamudeo (cu-curto) de Santiago Vega y una referencia literaria. En mi criterio, la poesía de Cucurto constituye un intento eminentemente literario por crear un espacio para la exploración de los lazos de unión entre migración, cultura -la música popular en particular-, crimen y sexo, elementos reunidos subsecuentemente para crear una estética del robo discursivo, de algún modo análoga a la economía del usufructo que se puede apreciar en el proyecto Cartonera. De este modo la obra de Cucurto materializa el vínculo entre el activismo cultural y la migración económica, en particular esos 
movimientos migratorios que rara vez antes recibieron atención académica o mediática en Argentina.

\section{Desplazamiento y migración}

Me gustaría examinar a continuación algunos aspectos relacionados con el desplazamiento, la migración y la poesía con referencia a una de las obras más conocidas de Cucurto, La máquina de hacer paraguayitos (1999). Lo plantearé mediante un contraste con otras dos representaciones de la diáspora dominicana, las constituidas por La fiesta del Chivo, de Mario Vargas Llosa, y The Brief Wondrous Life of Oscar Wao, de Junot Díaz.

El libro de Cucurto incluye en la página anterior a la portada un texto intrigante, una copia de un comprobante inmigratorio a nombre de Norberto Vega, sellado en Encarnación, expedido por la Dirección general de Migraciones del Ministerio del Interior de Paraguay con validez para treinta días contados desde el 23 de enero de 2000 y firmado por Zunilda C. Riveros. Norberto Santiago Vega es el nombre completo real de Cucurto y, casualmente, la ex-mujer de Vega es paraguaya. Si uno de los aspectos principales del neoliberalismo se cifra en un mayor control y regulación de la fronteras, en particular de las que no aportan beneficios para los capitalistas, La máquina comienza con un delicado acto de equilibrismo en y sobre la frontera. Comparece en ese comienzo de la historia un argentino de la periferia de Buenos Aires, en concreto de la municipalidad de Quilmes, que cruza la frontera hacia el norte, hacia un país más pobre, por tanto en sentido opuesto al camino que normalmente es frecuentado por muchos otros de los personajes del autor. Lo singular es que ese argentino cruza a Paraguay no por uno de los pasos fronterizos turísticos habituales -los preferidos por los nиеvos ricos de los años de Menem; Iguazú, por ejemplo-, sino que lo hace justamente por Encarnación. Esto es, por el paso con Posadas, en la provincia de Misiones, lugar asociado con el contrabando y el comercio semi-ilegal o sencillamente ilegal de mercancías. Este viaje se cuenta bajo el nombre real del autor, no con su seudónimo, y la evidencia del mismo es un documento oficial robado (los comprobantes normalmente se devuelven a la salida del país). El nombre del signatario, Zunilda, es un nombre femenino algo común en el Paraguay. Sus exóticos orígenes germánicos evocan al mismo tiempo la historia oculta de la llegada a Paraguay de alemanes nazis y supremacistas de la raza aria al término de la Segunda Guerra Mundial. De este modo, los dos nombres reunidos sugieren una serie de luchas de poder inscritas en términos nacionales, de clase y de género. Se da un juego en el que la inventiva y genialidad de la persona que cruza la frontera, ocultando su verdadera identidad o robando otra y desafiando a los representantes de la autoridad, se enfrenta a la imposición de las 
obligaciones impuestas por la fuerza controladora del estado. Pero, por supuesto, una cosa es robar un trozo de papel y otra muy distinta robar una obra completa. La máquina comienza con el siguiente epígrafe:

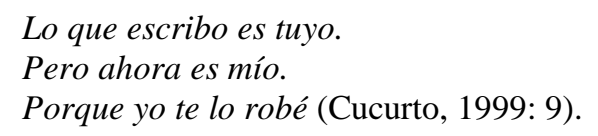

La primera línea resulta una típica dedicatoria dirigida al lector y a la vez una afirmación del estatus del lector como figura esencial para la interpretación y la existencia de la obra, posición esta que recordará mucho los intentos de la crítica literaria de la segunda mitad del siglo XX por minimizar la intención autorial como factor decisivo para la interpretación de su obra (Roland Barthes es quizás la figura más representativa en este terreno, pero son numerosos los ejemplos aducibles en la teoría francófona y en otras tradiciones). El uso de puntos para dividir las líneas de un modo que no encaja del todo bien con los dictados del buen estilo sintáctico reafirma el conflicto entre las proposiciones y apunta asimismo hacia una característica distintiva del estilo de Cucurto, los errores gramaticales.

El enfrentamiento entre la interpretación de la poesía por parte del autor y la interpretación del lector se diluye a continuación con la afirmación sobre la estética del robo que domina la obra de Cucurto. De un regalo pasamos a una declaración de autoría y después volvemos al robo con un nuevo entendimiento sobre el regalo original. No es que el autor regalase la obra al lector: ocurre que esta era ya en su origen del lector, a quien le fue sustraída. Lo que Cucurto escribe habría pertenecido antes (siempre) a otra persona. Su proyecto como autor se basa, pues, en el robo. Sin embargo, esto sólo resalta lo que se podría entender como la acumulación cultural primitiva presente en la literatura, por la que la autoría de palabras, frases y fenómenos que circulan libremente en una cultura resulta reclamada bajo el nombre de un autor. La imposibilidad de identificar el "yo" (Cucurto, Vega, ¿otra persona?) enfatiza esta incertidumbre. Como un plagiario confeso, Cucurto llama de este modo la atención sobre las estructuras de poder que sostienen la autoría.

La máquina explora en detalle cuestiones de migración y marginación en Buenos Aires, en particular a partir de la figura de la Dominicana, una mujer a la que se dirigen muchos de los poemas de la obra o -en algunos casos- desde cuyo punto de vista están escritos. La Dominicana aparece por primera vez en "Día tras día un trío de mujeres":

Y tú, dominicana del demonio, que lo único que haces es dejarme chupado como un higo.

Pasas las mañanas escuchando salsa, merengue, chachachá. ¡Que tu Willie Chirino! 
Migración y activismo literario: la intervención social y poética...

\author{
¿Que tu Jerry Rivera! Si yo fuera Willie \\ Chirino te daría salsa de patadas, un \\ Merengue de escupidas. Tú y tus tres primas \\ libidinosas, que impúdicamente imponen al \\ centro de la mesa a sus novios senegalíes y \\ marroquíes [...] \\ Si no fuera porque \\ cuando paseas por Corrientes enloqueces \\ libreros a granel, ¡uf!, judíos harapientos, \\ dueños de los libros hermanos de la dicha (Cucurto, 1999: 15-16).
}

Vemos de nuevo una serie de referencias literarias locales: la escena se ambienta en un conventillo, con los harapientos vendedores que son habituales en la novelística de Roberto Arlt, por ejemplo en El juguete rabioso (1926), y en otro momento aparece un «pichiciego» (16), el animal metafórico de la novela de Rodolfo Fogwill sobre la guerra de las Malvinas, titulada precisamente Los pichiciegos (1983). Son referencias que comparten un espacio cultural común con ciertas figuras populares igualmente presentes en los textos, incluyendo al salsero cubano Willie Chirino y a su homólogo puertorriqueño Jerry Rivera, ambos desde esa ostentación de unos nombres anglicanizados. Se presenta de esta forma un mundo a la vez marcado por la violencia, una sexualidad muy gráfica y los referentes de la inmigración y el trabajo mal remunerado, pero también por una potente intertextualidad. Con todo, lo que más llama la atención es la formulación de la voz poética: ese uso de una segunda persona "tú" en lugar del vernáculo "vos" es una característica de la condición de extranjero; a la vez, una serie de interjecciones y exclamaciones rompen el curso de la narración a favor de intervenciones expresivas de carácter violento o sexual. Inventar con y desde el lenguaje es la característica más típica de la discursividad propia de Cucurto, siguiéndose para ello flujos de pensamientos o conexiones tanto metonímicas como metafóricas. Mediante esos procedimientos, todo resulta posible en su lenguaje, tal y como se afirma en la fotocopia de una nota escrita a mano que abre su reciente El amor es mucho más que una novela de 500 páginas (2009: 2): «La literatura debe ser un espacio, ok, creación, un lugar, ¿un mundo? donde todo es posible».

La migración hacia Buenos Aires tiene una significación especial en el mundo representado en las obras de Cucurto. Como ha señalado Solberg en su importante estudio comparativo sobre la inmigración a Argentina y a Chile a comienzos del siglo XIX, «all the ills of the cities were laid on the shoulders of the foreign born» (1970: 94), muy en particular los problemas de prostitución y crimen (101). Otero y Pellegrino (2003) han documentado que en la capital argentina la concentración geográfica de los inmigrantes es relativamente baja (81). En Buenos Aires, «the conventillos encouraged a kind of "melting pot" at the bottom of the social pyramid» (102). Los autores hablan 
de un «postmigratory social space» (105) en el que se localizan nuevas redes multiétnicas.

En la obra de Cucurto la elección de inmigrantes dominicanos como figuras centrales, incluso muchas veces como narradores, alcanza gran relevancia. Es curioso que, frente a la importancia otorgada a la inmigración europea de fines del siglo XIX y principios del siglo XX, en los estudios sobre la historia y la cultura argentinas, olas de inmigración más recientes hayan atraído mucho menos la atención ${ }^{5}$. Quizás sea así debido a su conformación dentro de lo que Jones ha descrito como «the informal, illegal or vernacular city» (2006: 242), condición esta que aparece bien recogida en el poemario Hatuchay (Cucurto, 2007) con descripciones casi fotográficas del barrio de Once: el mercado repleto de zapatos brasileños, mano de obra industrial y doméstica paraguaya, supermercados coreanos, comida china o italiana y prostitutas dominicanas o del norte argentino (20-21).

La inmigración dominicana a Argentina es un caso particularmente curioso. La "biografía" de Cucurto explica que llegó a Buenos Aires a principios de los años 70, una fecha coincidente con la época de emigración masiva desde la República Dominicana. Ramona Hernández, en su estudio sobre los movimientos migratorios dominicanos (2002: 24) perfila las causas del éxodo registrado a partir de la caída del dictador Rafael Leónidas Trujillo, en 1962. En efecto, mientras que Trujillo estimuló el incremento poblacional e instauró un estricto control sobre la expedición de pasaportes, la intención del presidente Joaquín Balaguer fue de signo bien distinto. Balaguer estimuló de hecho un cambio profundo en la actividad económica, con deriva desde la agricultura hacia los sectores comercial e industrial a través del aumento de la inversión extranjera y permitiendo la salida del país a una gran cantidad de la población. Como gobernante autoritario, con más intensidad a partir de los años 70, la acción política de Balaguer se orientó no solo a echar del país las voces y personas indeseables que atacaban al régimen sino también hacia una expedición indiscriminada de pasaportes a todo el que lo solicitara, todo ello con la obvia finalidad de aliviar la alta presión demográfica. En parte como resultado de estas políticas y de las correlacionadas con el crecimiento del turismo, la República Dominicana ha pasado a ocupar un papel destacado en el comercio sexual internacional. En primer lugar, como observa Amalia L. Cabezas (1999: 110), el país tiene una de las industrias sexuales per capita más importantes del mundo; en segundo lugar, las mujeres dominicanas desempeñan un papel predominante en la migración internacional relacionada con el trabajo sexual (112). El dinero procedente de esas actividades supuso más o menos la cuarta parte de la moneda extranjera ingresada a la República en los años 80 (Kempadoo, 2004: 164). Tan

\footnotetext{
${ }^{5}$ Sobre inmigraciones recientes a Argentina véase Grimson y Jelin, eds. (2006) y Grimson (1999).
} 
importantes fue $\mathrm{y}$ es el número de trabajadores sexuales y los movimientos poblacionales relacionados con el sexo en la República Dominicana que Kempadoo llega a sostener que la sexualidad opera como «a potentially transformational dimension of the region» (205).

Existe en cualquier caso un notable contraste entre la versión de la migración dominicana ofrecida por Cucurto y las otras dos representaciones literarias de éxito internacional antes mencionadas: La fiesta del Chivo, de Mario Vargas Llosa (2000), y La maravillosa vida breve de Óscar Wao, de Junot Díaz (2008). El Nobel peruano (naturalizado español) Vargas Llosa se centra en el caso de un personaje privilegiado en términos socioeconómicos, la abogada Urania Cabral, hija de uno de los consejeros de Trujillo, a quien de niña sus profesoras monjas sacaron del país durante los últimos días del régimen, después de que el entonces impotente anciano que señoreaba el país tratara de violarla. Una práctica ésta que se había reiterado sin encontrar mayor impedimento con otras muchas mujeres dominicanas, ejerciendo de ese modo Trujillo el perverso droit de seigneur que él mismo se había autorizado como dictador. Traumatizada tras el horrible evento, descrito con escabroso detalle en la obra de Vargas Llosa, Urania será incapaz de mantener relaciones sexuales a lo largo de toda su vida. Su vuelta posterior a la isla sirve como una mecha para la narración: los encuentros con sus parientes nos ofrecen la oportunidad de revivir el golpe y lo que sucedió a continuación, así como la complicidad de su propio padre en el intento de violación, pues éste la había enviado a visitar al dictador con total conocimiento de las inclinaciones del Chivo, en un intento por salvar su propia carrera política.

La novela de Vargas Llosa se permite ciertas libertades históricas, por ejemplo omitiendo varios años de la historia dominicana y obliterando todas las alternativas políticas al margen de las identificadas con el salvaje clan de Trujillo o con la realpolitik de Balaguer. En La Fiesta sale ganando el conservadurismo político y su plasmación en un Balaguer que tomaría posiciones a favor de los Estados Unidos. Pero dada la ausencia de personajes atractivos (las motivaciones dominantes en toda la obra son el egoísmo, la avaricia y la lujuria), lo más revelador en términos de intriga narrativa es el manejo de un tono investigativo o periodístico, el impulso que los lectores experimentan por descubrir qué fue lo que verdaderamente ocurrió, que fue lo que le pasó a Urania. Así, la descripción de la escena sexual que centra el argumento se aplaza constantemente, tanto en la trama del presente como en la del pasado. De modo que la novela establece una teleología del descubrimiento que imita el modo y la decepción de aquella violación medio cometida. Logra reforzarse así el victimismo de Urania y su obsesiva compulsión por la repetición, en un acto renovado de fidelidad al dictador y a sus estructuras de poder. Mientras, a través de Urania, se intenta convertir 
al escritor en una suerte de héroe narrativo. Pero lo que queda en su lugar no es sino la incapacidad del pragmatismo liberal para juzgar la violencia machista, así como para poner en claro en términos históricos su dependencia simultánea de las propias estructuras dictatoriales y de la interferencia colonial del norte.

La novela de Junot Díaz, ambientada en la diáspora dominicana en Estados Unidos, incluye una serie de extensas y detalladas notas a pie de página sobre la reciente historia dominicana escritas en un estilo que desvela una condición vernácula y humorística en asociación con una colección desordenada de historias ficcionales de apariencia semi-autobiográfica. Al igual que en el caso de Vargas Llosa -a quien el narrador de La maravillosa vida breve de Óscar Wao fustiga por su tratamiento positivo de Balaguer en La fiesta del chivo (2008: 90)-, el sexo es la forma de violencia política más utilizada en la novela de Díaz, ya sea como vehículo de dominación de los súbditos femeninos por Trujillo y sus guardaespaldas, ya sea en lo que podrían describirse como violaciones de castigo o mediante las salvajes palizas infligidas a los personajes implicados en actos sexuales considerados transgresivos.

El protagonista de la novela de Junot Díaz acaba siendo asesinado por su aventura con la mujer de un capitán de la policía militar. La posibilidad de escapar de la maldición del colonialismo, a la que a lo largo de la novela se hace referencia como Fukú, es muy limitada. Solo se vislumbra en el misterioso manuscrito con una supuesta cura para lo que nos aflige, que Óscar redacta a lo largo de la última parte de la novela, pero que nunca se concreta y que el lector no alcanza a ver. La novela corrige muchas de las manipulaciones histórico-políticas de Vargas Llosa, pero queda en el aire la posibilidad de un futuro digno para los dominicanos, al margen del contexto metatextual de la migración a los Estados Unidos y en términos individuales de una carrera literaria y académica de éxito.

El personaje de Cucurto como poeta dominicano resulta también paradójico. La República Dominicana no es un país particularmente famoso por sus poetas, como sí lo son por el contrario varios de los países vecinos (Cuba y Nicaragua serían tal vez los más reconocidos). Se da la circunstancia, por ejemplo, de que en dos recientes antologías de poesía latinoamericana la República Dominicana cuenta con muy escasa representación. En la antología de Julio Ortega (1997) aparecen tres poetas, y son sólo dos en la de González y Araya, ZurDos (2005). Es más, uno de los poetas más conocidos de la República es el antiguo presidente Joaquín Balaguer, cuyo régimen «authoritarian and paternalistic» (Bell 1981: 99) es, podría afirmarse así, la causa ficticia por la que el ficticio Washington Cucurto abandonó el país. En la década de los 70 el régimen de Balaguer permitió la actuación de los escuadrones de la muerte, responsables de los asesinatos de numerosos opositores. En 1971, durante nueve meses, 
un grupo de jóvenes oficiales de policía conocido como La Banda atacó a organizaciones e individuos de izquierdas e incluso destrozó a tiros algunas escuelas. Según parece, siempre con el beneplácito de sus mandos (101). Lo cierto es que a pesar de su dedicación política, prolongada hasta los noventa años de edad, Balaguer encontró tiempo para publicar una serie de poemarios.

Cucurto toma uno de los clichés más comunes sobre la identidad argentina y la inmigración y lo matiza para crear el retrato de una migración plebeya, en gran parte oculta, lo que le permite habilitar una correferencialidad permanente entre literatura, política y sexo. El personaje de La Dominicana es por ello central en La máquina. Una serie de poemas incluyen recuerdos contados desde su punto de vista y desde su lenguaje, como puede constatarse en la composición "Y he contribuido al bienestar nacional...":

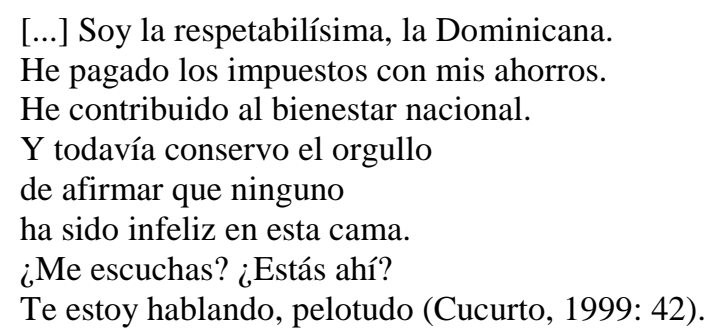

Buena parte del poema traza una serie de reminiscencias sobre la carrera y los viajes de La Dominicana, incluyendo Lima, Panamá y Venezuela. Tras algunos periplos por distintos lugares y épocas, cubriéndose un periodo de treinta años y un trayecto por varios países, el poema se centra en el tenso ambiente de una pieza. En ella se sitúa a los lectores mediante la expresión «esta cama». Las condiciones económicas en las que se desarrolla la vida de La Dominicana es la común al modo de trabajo sexual de muchos inmigrantes, que pagan impuestos legales correlativos a un trabajo ilegal, lo cual conlleva el hecho de no recibir ninguno de los beneficios de los que otros contribuyentes sí disfrutan, factor compatible de todos modos con un orgullo profesional asociado a sus probadas habilidades sexuales. Sin embargo, en las dos últimas líneas del poema, la interpelación a un interlocutor explícitamente masculino y desconocido (¿el lector?, ¿el escritor?) constituye un ataque directo y ofensivo al lector y a las figuras de Cucurto y Vega, quienes por un lado se beneficiarían de la situación referida y por otro la ignorarían cuando así les conviene. El poema cuestiona por tanto el papel tanto del lector como del escritor en la explotación sexual de las mujeres. Demuestra la tensión latente entre las restricciones económicas y los intereses personales, en los que una mujer se ve obligada a ejercer el único trabajo que le queda, un trabajo sexual, valorado a la vez en términos aparentemente sociales. Esta curiosa adhesión conservadora al sistema capitalista de sus miembros más marginados tiene el 
efecto de resaltar la hipocresía latente tras las reivindicaciones de una base ética en el capitalismo.

La máquina concluye con una reveladora biografía de Cucurto. Según el corto texto que se incluye al final del volumen y que firma Santiago Vega, «agitador cultural [que] se dedica desde hace años a compilar la obra de Washington Cucurto» (1999: 61), éste nació en la República Dominicana en 1942 y llegó a Buenos Aires a comienzos de la década de los 70. A continuación siguen una serie de referencias tanto reales como ficticias a trabajos de Vega/Cucurto, así como información sobre sus viajes por Argentina, las provincias del interior y algunos países limítrofes, hasta llegar a desaparecer en América Central allá por 1979. Tamara Kamenszain ha señalado que, entre todas estas encrucijadas (un argentino haciéndose pasar por dominicano con una máquina para hacer paraguayos), La máquina «trabaja, como una inmigración latinoamericana, invadiendo todo, ocupando los lugares, rompiendo las escrituras» (2007: 130). La interpelación de la Dominicana al lector y al escritor sería así una reclamación de un espacio civil propio y una llamada de atención realizada desde una de las posiciones más marginadas y desventajadas, algo que se hace eco de las prácticas de la empresa editorial de Cucurto. La reflexión puesta en boca de La Dominicana llama la atención sobre el variable estado político de la poesía (si se piensa, por ejemplo, en contraste con los versos patrióticos del presidente Balaguer) y sobre el trabajo necesario para evitar que ésta se convierta en simple propaganda política para el sistema o para el espectador apolítico, haciendo en fin un llamamiento por un arte divorciado de la cruda vida política. Friera (2007) señala que, sea como fuere, el personaje Cucurto no debería ser confundido con el autor Vega, a pesar de que «equívocos» de esta índole aparecen reiteradamente en los medios de comunicación.

Cucurto/Vega ha utilizado otro seudónimo, el de Humberto Anachuri. Complicando un poco más las cosas si cabe, Anachuri, «electricista paraguayo y crítico» (Anachuri, 2005), es autor de una reseña sobre una de las novelas de Cucurto, Las aventuras del Sr. Maíz, publicada en la página web de la editorial. A mayores, en la solapa de El curandero de amor (2006), los detalles bibliográficos de Santiago Vega se dan como si fueran los de Cucurto. Ofreciendo alguna claridad sobre el sistema de escritura propio de Cucurto, una entrevista en la revista bonaerense La novia de Tyson recoge las siguientes reflexiones sobre su idea del plagio como «una auténtica variante de la literatura»:

Yo no afano, simplemente escribo "a la manera de"; aparte ni el más genial creador podría plagiar magistralmente como yo. Si plagiamos al plagiario, saldrá algo maravilloso, lo mismo si plagiamos a un muerto [...] pues no se lo puede hacer peor [...]; en estos casos el plagio es siempre progresista y por consecuente productivo, al igual que el peronismo. El plagio es ante todo un acto de amor peronista... Perón le afanaba a Mussolini, Menem a Reagan, Cortázar a Michaux (Cucurto, 2005: 60) 
Dejando a un lado la quizás sorprendente inclusión de Julio Cortázar, un escritor conocido por su desacuerdo con las políticas peronistas, la noción de una tradición política y literaria del plagio resulta sorprendente, en particular al inscribirse en la historia del peronismo en sus diferentes versiones. De hecho, al igual que en la presentación de la inmigración dominicana a Argentina, comparece una curiosa nota de verosimilitud relativa a la condición de Cucurto como peronista popular. Según han señalado Lupu y Stokes, desde la reinstauración de la democracia la polarización de las clases, con los sectores más bajos a favor del peronismo y «the Peronist Party again representing the poor», se ha vuelto a convertir en una especificidad de la política argentina (2009: 58, 81). Cucurto, el plagiario, es por tanto un usurpador literario, igual que Perón fue un plagiario de los fascismos europeos y de las culturas populares locales. Incluso más: Cucurto redescubre el canon argentino como una serie de robos. Según lo explicado en otra entrevista, «Borges era un chorro» (Capelli, 2006). De este modo Cucurto se integra en una tradición literaria y política del robo, incluyendo en ella el "Pierre Menard" de Borges, el uso del diálogo grabado de Puig, el robo de libros del personaje de Arlt en El juguete rabioso (1926), el plagio por Perón de las políticas de Mussolini y de la sonrisa de Gardel. Los productivos robos creativo-literarios de Cucurto se reconvierten en una intervención política. De modo que la economía del usufructo latente en el proyecto Eloísa Cartonera se transforma en la obra literaria de Cucurto en una poética del robo. Su escritura muestra no solo la gran variedad de la inmigración en Argentina y sus consecuencias políticas inesperadas sino también el potencial de las intervenciones poéticas en las que activismo y poesía vienen encontrando un balance entre ética y estética.

Aun así, creo que concentrar toda la atención en el contexto y el contenido de la poesía de Cucurto, en su referencialidad histórica y en su representación de la inmigración semioculta, el trabajo sexual y los bailes de cumbia, no hace más que oscurecer el complejo trabajo literario consistente en desmenuzar y recomponer el canon argentino. Los medios a través de los cuales la poesía puede intervenir políticamente no están limitados a una serie de elecciones binarias. En realidad, forman parte de una red estética, temática y de selecciones prácticas que afectan su composición, su circulación y la ulterior recepción. A veces la poesía encuentra su éxito justo en aquello en lo que en relación con otros géneros literarios sería descrito como un fracaso. 


\section{Referencias bibliográficas}

ALARCÓN, C. (2009): Cuando me muera quiero que me toquen cumbia: Vidas de pibes chorros. Buenos Aires, Kapelusz/Norma.

ANACHURI, H. [Norberto Santiago Vega] (2005): Reseña de Washington Cucurto, Las aventuras del Sr. Maíz, en http://www.interzonaeditora.com/ titulos/titulo.php?idTitulo=43\&idAutor=8 [última consulta, 21-8-2008].

BELL, I. (1981): The Dominican Republic. Boulder/London, Benn.

BORGES, J. L. (2009): Obras completas. I. Buenos Aires, Emecé.

BRIL, T. (2004): "Profile of Eloísa Cartonera", New Internationalist, 366 (April 2004), en http://www.newint.org/columns/makingwaves/2004/04/01/eloisa-cartonera/ [última consulta, 2-7-2009].

BUENO, M. (2007): "Vidas literarias en la Argentina contemporánea: tres nombres de autor", Margens/Márgenes, 9/10 (enero-junio 2007) pp. 60-71.

CABEZAS, A. L. (1999): "Women's Work is Never Done: Sex Tourism in Sosúa, the Dominican Republic”, en K. KEMPADOO, ed., Sun, Sex, and Gold. Tourism and Sex Work in the Caribbean. Oxford/New York, Rowman \& Littlefield, pp. 93-124.

CAPELLI, M. (2006): "Borges era un chorro", (entrevista con Washington Cucurto), Los inrockuptibles, en http://www.losinrockuptibles.com/cucurto.htm [última consulta, 18-8-2009].

CARRERA, A. ed., (2001): Monstruos. Antología de la joven poesía argentina. Buenos Aires, FCE.

CUCURTO, W. [Norberto Santiago Vega] (1999): La máquina de hacer paraguayitos. Buenos Aires, Mansalva, 2005.

- (2003): La Cartonerita. Bahía Blanca, VOX.

- (2005): Como un paraguayo ebrio y celoso de su hermana. Bahía Blanca, VOX.

- (2006): El curandero de amor. Buenos Aires, Emecé.

(2007): Hatuchay. Bahía Blanca, VOX.

_- (2009a): El amor es mucho más que una novela de 500 páginas. Buenos Aires, Eloísa Cartonera.

- (2009b): El tractor. Buenos Aires, Eloísa Cartonera.

DE GORI, E. (2005): "Notas Sociológicas sobre la Cumbia Villera. Lecturas del Drama Social Urbano", Convergencia, 38 (mayo-ago 2005), pp. 353-372.

DÍAZ, J. (2008): The Brief Wondrous Life of Oscar Wao. London, Faber \& Faber.

EPPLIN, C. (2007): "New Media, Cardboard, and Community in Contemporary Buenos Aires", Hispanic Review, Autumn 2007, pp. 385-398.

FERNÁNDEZ L'HOESTE, H. (2007): “All Cumbias the Cumbia: The Latin Americanization of a Tropical Genre", en S. SHUKLA - H. TINSMAN, eds., Imagining Our Americas. Durham/London, Duke UP, pp. 338-364. 
FRIERA, S. (2007): "Washington Cucurto y el mundo según «el curandero de amor»", en http://www.elortiba.org/cucurto.html [última consulta, 13-8-2008].

(2008): "Hay un espíritu más o menos anarco que nos abarca a todos", Pagina/12

3 junio 2008, en http://www.pagina12.com.ar/diario/suplementos/espectaculos/210245-2008 [última consulta, julio 2009].

GIRONDO, O. (1922): Veinte poemas para ser leídos en el tranvía. Calcomanías. Buenos Aires, Losada, 1996.

GONZÁLEZ, Y. - ARAYA, P. (2005): ZurDos. Última poesía latino americana. Madrid, Bartleby.

GRIMSON, A. - JELIN, E. eds. (2006): Migraciones regionales hacia la Argentina: diferencia, desigualdad y derechos. Buenos Aires, Prometeo.

GRIMSON, A. (1999): Relatos de la diferencia y la igualdad. Los bolivianos en Buenos Aires. Buenos Aires, Eudeba.

HERNÁNDEZ, R. (2002): The Mobility of Workers under Advanced Capitalism: Dominican Migration to the United States. New York/Chichester, Columbia UP.

JONES, G. A. (1994): "The Latin American City as Contested Space: A Manifesto", Bulletin of Latin American Research, 13/1, pp. 1-12.

- (2006): "Culture and Politics in the «Latin American» City", Latin American Research Review, 41/1 pp. 241-260.

KAMENSZAIN, T. (2007): La boca del testimonio. Lo que dice la poesía. Buenos Aires, Norma.

KANT, I. (1790): Critique of Judgement. trad. James Creed Meredith. Oxford, Oxford University Press, 2007.

KEMPADOO, K. (2004): Sexing the Caribbean. Gender, Race and Sexual Labour. London/New York, Routledge.

KILNGER, D.I. (2007): Escritas de si, escritas do outro: o retorno do autor e a virada etnográfica. Rio de Janeiro, 7letras.

LIBERTELLA, H. ed. (2002): Literal, 1973-1977. Buenos Aires, Santiago Arcos.

LUDMER, J. (2007): "Literaturas postautónomas", en http://www.lehman.cuny.edu/ ciberletras/v17/ludmer.htm [última consulta, 17-9-2009].

LUPU, N. - STOKES, S.C. (2009) "The Social Bases of Political Parties in Argentina, 1912-2003”, Latin American Research Review, 44/1, pp. 58-87.

ORTEGA, J. (1997): Antología de la poesía latinoamericana del siglo XXI. El turno y la transición. Mexico DF/Buenos Aires, Siglo XXI, $2^{\mathrm{a}}$ ed., 2001.

OTERO, H. - PELEGRINO A. (2003): "Sharing the City: Residence Patterns and Immigrant Integration in Buenos Aires and Montevideo," en BAILY, S. L. MíGUEZ, E. J. eds., Mass Migration to Modern Latin America. Wilmington, Scholarly Resources, pp. 81-112. 
PADILLA, M. (2007): Caribbean Pleasure: Tourism, Sexuality, and AIDS in the Dominican Republic. Chicago, University of Chicago Press.

PORRÚA, A. (2008): “Un barroco gritón”, Punto de vista abril/mayo 2008, en http://www.bazaramericano.com/resenas/articulos/negros_porrua.htm [última consulta, 21-8-2009].

SAER, J. J. (1994): La pesquisa. Buenos Aires, Seix Barral, 2006.

SARLO, B. (2006): "La novela después de la historia. Sujetos y tecnología", en Escritos sobre literatura argentina. Buenos Aires, Siglo XXI, 2007, pp. 471-482.

SOLBERG, C. (1970): Immigration and Nationalism. Argentina and Chile, 1890-1914. Austin/London, University of Texas Press.

VARGAS LLOSA, M. (2000): La fiesta del chivo. Buenos Aires, Alfaguara, $11^{\mathrm{a}}$ ed., 2001.

VERBITSKY, B. (1957): Villa miseria también es América. Buenos Aires, Paidós, $4^{\text {a }}$ ed., 1967.

YÚDICE, G. (2003): The Expediency of Culture. Uses of Culture in the Global Era. Durham NC/London, Duke University Press. 